\title{
I.UMIBUNG
}

\section{TATA RUANG AGROFORESTRY LAHAN KAMPUS II POLITEKNIK PERTANIAN NEGERI PAYAKUMBUH JORONG BATU KABAU NAGARI SITANANG}

\author{
Amrizal $^{1}$, Fazlimi ${ }^{1}$, Deswani Panggabean ${ }^{1}$ \\ ${ }^{1}$ Politeknik Pertanian Negeri Payakumbuh \\ Korespondensi: maulinafri@yahoo.co.id
}

\begin{abstract}
Diterima : 27 Agustus 2020
Disetujui : 29 Agustus 2020

Diterbitkan : 31 Agustus 2020
\end{abstract}

\begin{abstract}
Land management with an agroforestry system aims to maintain the amount and diversity of land production, so that it has the potential to provide social, economic and environmental benefits (Senoadji, 2012). In the concept of agroforestry spatial planning on campus land II Payakumbuh State Agricultural Polytechnic is quite possible to be implemented by collaborating between current agricultural activities with standing trees (forests) that are beneficial to ecology and sustainability, comforting the surrounding environment. From the results of the study obtained five plant and fisheries species composition in the land of Campus II Payakumbuh State Agricultural Polytechnic, namely estate crops (rubber, sugar cane), fruit trees (guava, matoa, mango, orange), food plants (lowland rice) ), fodder grass (elephant grass) and fisheries (tilapia, tilapia fish and carp). Two agroforestry systems that can be applied for soil and water conservation on the land of Campus II Payakumbuh State Agricultural Polytechnic, namely Agrisilvikultur and Agrosilvofishery, which are respectively: $62,770 M^{\wedge} 2$ and $12,128 M^{\wedge} 2$.
\end{abstract}

Keywords : agroforestry, agrisilvikultur, agrosilvofishery

\section{PENDAHULUAN}

Lahan Kampus II Politeknik Pertanian Negeri Payakumbuh, terletak pada $100^{\circ} 45^{\prime}$ 50' BT (Bujur Timur) dan $0^{0}$ 16'30' LS (Lintang Selatan), Jorong Batu Kabau, Nagari Sitanang, Kecamatan Lareh Sago Halaban. Kondis lahan kampus II adalah berbukit dan sebelah selatan berbatasan dengan sungai batu kabau, yang digunakan sebagai lahan praktek lapangan bagi mahasiswa Politeknik Pertanian Negeri Payakumbuh semenjak tahun 2011.

Karakteristik lahan adalah sifat lahan yang dapat diukur dan diestimasi. Dari beberapa pustaka disebutkan bahwa penggunaan karakteristik lahan untuk keperluan evaluasi lahan bervariasi. Adapun karakteristik lahan yang digunakan dalam menilai lahan adalah temperatur rata-rata tahunan, curah hujan (tahunan atau pada masa pertumbuhan 


\section{I.UMIBUNG}

tanaman), kelembaban udara, drainase, bahan kasar, kedalaman efektif, alkalinitas, kedalaman sulfida, lereng, batuan di permukaan, singkapan batuan, bahaya longsor, bahaya erosi serta tinggi dan lama genangan. Sementara itu evaluasi lahan adalalah proses pendugaan tingkat kesesuaian lahan untuk berbagai alternatif penggunaan lahan, baik untuk pertanian, kehutanan, pariwisata, konservasi lahan, atau jenis penggunaan lainnya (Caya et al, 2014).

Pengelolaan lahan dengan sistem agroforestry bertujuan untuk mempertahankan jumlah dan keragaman produksi lahan, sehingga berpotensi memberikan manfaat sosial, ekonomi dan lingkungan (Senoadji, 2012). Dalam konsep tata ruang agroforestry di lahan kampus II Politeknik Pertanian Negeri Payakumbuh cukup memungkinkan untuk dilaksanakan dengan mengkolaborasikan antara kegiatan pertanian yang sedang berjalan saat ini dengan tegakan pepohonan (hutan) yang bermanfaat bagi ekologi dan kelestarian, kenyamanan lingkungan di sekitarnya.

Untuk mencapai konsep diatas, perlu adanya pengaturan ruang dan pola desain tata ruang agroforestry. Dalam hal ini, ruang yang utama yang harus ada adalah ruang budidaya pertanian dan ruang hutan dengan tegakan pohon. Sementara ruang penunjang antara lain adalah welcome area, ruang service dan ruang rekreasi. Untuk vegetasi, seluruh komoditi akan dipadukan agar tercipta komposisi agroforestry yang berfungsi dan berestetika (Hadi et al, 2013).

\section{METODOLOGI PENELITIAN}

Penelitian ini dilakukan pada lahan kampus II Politeknik Pertanian Negeri Payakumbuh, yang terletak di Jorong Batu Kabau Nagari Sitanang Kecamatan Lareh Sago Halaban. Penelitian ini dilakukan selama 06 bulan yaitu bulan 12 Mei 2019 sampai November 2019.

Alat dan bahan yang dibutuhkan dalam pelaksaaan penelitian ini adalah GPS, kamera digital, Software ArcGis, Peta Kontur Lahan, Peta Zonasi Lahan, Flash disk / CD dan Alat-alat tulis

Adapun tahapan pengerjaan penelitian yang dilakukan adalah :

Persiapan yang dilakukan, antara lain:

1. Studi kepustakaan serta penelitian yang berhubungan dengan topik serta obyek daerah penelitian. 


\section{I.UMIBUNG}

2. Interpretasi dan analisis peta yang meliputi:

a. Peta lereng atau peta kontur lahan, untuk mengetahui kemiringan lereng di daerah penelitian.

b. Peta zonasi lahan, untuk mengetahui macam penggunaan lahan di daerah penelitian.

3. Menentukan titik koordinat pengambilan sampel di lapangan.

Pengamatan lapangan dilakukan dengan mengamati parameter-parameter yang menjadi objek penelitian pada setiap lokasi pengamatan yang sudah ditentukan. Berikut adalah tahapan pengamatan yang dilakukan di lapangan:

a. Pengambilan titik koordinat yang menggunakan alat GPS.

b. Mengamati berbagai karakteristik lahan, tanah dan pengambilan dokumentasi lahan.

Tahapan berikutnya adalah pengolahan data yang didapat dari lapangan baik itu data koordinat, elevasi luasan yang bisa di kembangkan untuk agroforestry.

\section{HASIL DAN PEMBAHASAN}

Hasil pengambilan data lapangan berupa pengambilan data titik koordinat, dilakukan setelah pembukaan jalan rintisan. Pengambilan titik koordinat dilapangan dilakukan sebanyak $\pm \mathbf{1 0 0}$ titik. Data titik koordinat yang diambil adalah dalam format data Universal Transver Merkator (UTM). Data diolah supaya dapat menggambarkan kondisi lapangan. Data titik yang didapat dihubungkan untuk membuat batasan lahan dan pengelompokan komoditi tanaman berdasarkan pola Agrofrestry .

Data titik koordinat dihubungkan untuk mendapatkan luasan lahan dan pola agroforestry yang dijadikan pertimbangan dalam penetapan pola lokasi tata ruang agroforestry

Penelitian yang dilakukan menghasilkan informasi mengenai pengelolaan lahan dengan sistem agroforestry di lahan Kampus II Politeknik Pertanian Negeri Payakumbuh. Terdapat berbagai komposisi jenis tanaman penyusun agroforestry yang diusahakan maupun variasi komoditi agroforestry seperti terlihat pada Gambar 1. 


\section{I.UMIBUNG}

\section{oumentive}

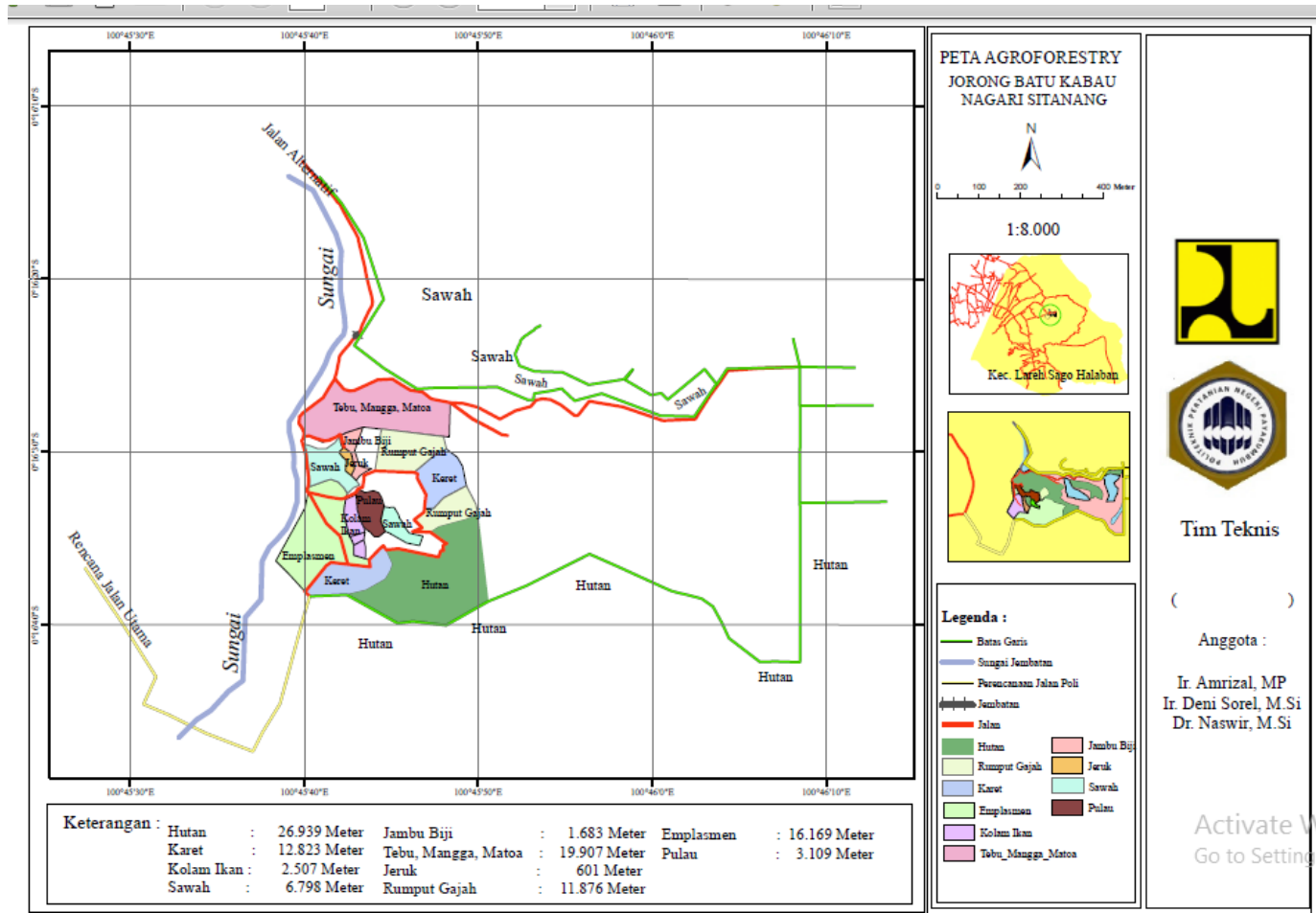

Gambar 1. Peta Sebaran Pola Agroforestry

\section{Komposisi Vegetasi}

Komposisi jenis tanaman yang ada di lahan Kampus II Politeknik Pertanian Negeri Payakumbuh adalah kombinasi antara komponen vegetasi berkayu berdaur panjang (tanaman perkebunan dan pohon buah-buahan) dengan tanaman pertanian berdaur pendek dan ikan. Secara umum komoditi yang ada pada lahan penelitian ini dapat dilihat pada Tabel 1.

Tabel 1. Komposisi Jenis

\begin{tabular}{cll}
\hline No & Kelompok Jenis & Jenis \\
\hline 1 & Tanaman Perkebunan & karet, tebu \\
2 & Pohon buah-buahan & jambu biji, matoa, mangga, jeruk \\
3 & Tanaman Pangan & padi sawah \\
4 & Rumput pakan ternak & rumput gajah \\
5 & Perikanan & ikan nila, ikan mujair, ikam mas \\
\hline
\end{tabular}

Komposisi tanaman yang terlihat pada Tabel 1, menggambarkan jenis tanaman yang beragam. Kelompok jenis tanaman perkebunan dan pohon buah-buahan merupakan 


\section{I.UMIBUNG}

kelompok vegetasi berkayu berdaur panjang yang merupakan kelompok utama dalam sistem agroforestry. Sedangkan kelompok jenis lainnya (tanaman pangan) mewakili komponen pertanian berdaur pendek yang dikombinasikan dengan kelompok rerumputan (pakan ternak) dan perikanan.

\section{Pola Agroforestry}

Sistem agroforestry merupakan kombinasi antara beberapa jenis pepohonan dengan tanaman semusim dengan atau tanpa ternak atau hewan pada satuan ruang yang sama baik bersamaan maupun berurutan (Widianto et al., 2003). Agroforestry juga merupakan perpaduan pola tanam dan kolaborasi antara berbagai macam kegiatan ekonomi, yang mengarah pada perbaikan kondisi lingkungan sehingga manfaat multifungsi dapat dirasakan (Maria et al., 2012) Lahan Kampus II Politeknik Pertanian Negeri Payakumbuh sudah menerapkan sistem agroforestry. Beberapa komposisi jenis penyusun sistem agroforestry menurut lansdcape dapat dilihat pada Tabel 2.

Tabel 2. Komposisi Jenis Penyusun Sistem Agroforestry Menurut Lansdcape

\begin{tabular}{cllc}
\hline No & \multicolumn{1}{c}{ Kombinasi Jenis } & \multicolumn{1}{c}{$\begin{array}{c}\text { Sistem } \\
\text { Agroforestry }\end{array}$} & Luasan $\left(\mathrm{M}^{\wedge} 2\right)$ \\
\hline 1 & Tebu + matoa + mangga & Agrisilvikultur & 19.907 \\
2 & Padi sawah + jeruk + jambu biji & Agrisilvikultur & 9.082 \\
3 & Karet + rumput gajah + jambu biji + jeruk + & Agrisilvikultur & 33.781 \\
& padi sawah & & \\
4 & Padi sawah + ikan + karet & Agrosilvofishery & 12.128 \\
\hline
\end{tabular}

Komponen penyusun sistem agroforestry pada Tabel 2. di lokasi penelitian tergolong dalam tipe agrisilvikultur dan agrosilvofhisery. Agrisilvikultur adalah sistem agroforestry yang mengkombinasikan komponen kehutanan (atau tanaman berkayu/woody plants) dengan komponen pertanian (atau tanaman non-kayu). Tanaman berkayu dimaksudkan yang berdaur panjang (tree crops) dan tanaman non-kayu dari jenis tanaman semusim (annual crops) (Sarjono et al., 2003). Sedangkan agrosilvofishery adalah sistem agroforestry yang mengkombinasikan komponen tanaman berkayu, tanaman semusim dan perikanan.

Lahan penelitian ini memiliki tingkat kemiringan 3\%-15\%. Menurut bentuk pengaturan dan komposisi tanaman tahunan pada kemiringan <15\% yaitu tanaman 


\section{I.UMIBUNG}

semusim 75\% dan tanaman tahunan 25\% (Yunasfi, 2007). Sistem agroforestry dinilai tepat sebagai upaya konservasi tanah dan air (Silaya dan Tjoa, 2013). Pemilihan jenis tanaman dalam sistem agroforestry selalu dikaitkan dengan kesesuaian lahannya (Albasri et al., 2015). Struktur dari tutupan kanopi dari sistem pertanian konservasi pola agroforestry berfungsi sebagai pengendali besarnya energi kinetik hujan yang akan mengenai tanah yaitu luasan dan bentuk strata dari tutupan kanopi akan mempengaruhi besarnya intersepsi butiran hujan dan jumlah percikan air hujan (Naharuddin, 2018).

Komposisi jenis penyusun sistem agroforestry pada Tabel 2. dimanfaatkan sebagai sumber pangan (padi sawah) serta sumber buah-buahan (matoa, jeruk, jambu biji, dan mangga). Pemanfaatan agroforestry sebagai pakan ternak juga memberikan manfaat terutama untuk memenuhi kebutuhan hewan ternak. Rumput gajah akan tumbuh lebih baik jika didampingi oleh tanaman yang lebih tinggi. Hal ini tentu sejalan dengan pola tanam agrofrestri yang memadukan antara tanaman strata bawah dengan strata menengah dan strata atas.

\section{KESIMPULAN}

Dari hasil penelitian yang dilakukan dapat disimpulkan bahwa :

1. Terdapat lima komposisi jenis tanaman yang terdapat di lahan Kampus II Politeknik Pertanian Negeri Payakumbuh, yaitu tanaman perkebunan (karet, tebu), pohon buahbuahan (jambu biji, matoa, mangga, jeruk), tanaman pangan (padi sawah), rumput pakan ternak (rumput gajah) dan perikanan (ikan nila, ikan mujair dan ikan mas).

2. Terdapat dua sistem agroforestry yang dapat diterapkan untuk konservasi tanah dan air pada lahan Kampus II Politeknik Pertanian Negeri Payakumbuh, yaitu Agrisilvikultur dan Agrosilvofishery yang luasan masing-masing adalah: $62.770 \mathrm{M}^{\wedge} 2$ dan 12.128 $\mathrm{M}^{\wedge} 2$.

\section{REFERENSI}

Albasri, S. A. Paembonan, S. Millang dan A. Ma'ruf. 2015. Desain Agroforestry Pada Lahan Kritis di Desa Kayu Loe Kecamatan Bantaeng Kabupaten Bantaeng. Ecogreen. Vol. 1 No. 1 ; 79-88.

Caya, Gunawan, T, Suprodjo, S.W, Muta'ali, L. 2014. Optimalisasi penggunaan lahan untuk agroforestry di Daerah Aliran Sungai Cimanuk Propinsi Jawa Barat. Jurnal Tekno Sains, Vol. 4 No. 1 ; 39-53.

Fahruni. 2017. Karakteristik lahan agroforestry. Jurnal Daun, Vol. 4 No. 1 ; 1-6. 


\section{I.UMIBUNC}

Hadi, A.A, Kaswanto, Baihaqi, M, Syah, C. 2013. Desain lanskap agroforestry calon hutan Kota Penggilingan Jakarta Timur. Lokakarya Nasional dan Seminar. Forum Komunikasi Perguruan Tinggi Pertanian Indonesia (FKPTPI). Bogor.

Kaswanto, Arifin, H.S, Munandar, A, Liyama, K. 2008. Sustainable water management in the rural landscape of Cianjur Watershed, Cianjur District, West Java, Indonesia. Journal International Society for Southeast Asian Agriculture Sciences (ISSAAS) $14 ; 33-45$.

Kusumandari, A, Irawati, D, Soedjoko, S,A. 2015. Optimalisasi penggunaan lahan dengan sistem agroforestry dan pendampingan pascapanennya di kelompok tani Dusun Kemuning, Gunung Kidul. Indonesian Journal of Community Engagement, Vol. 01, No. $01 ; 1-13$.

Maria, R., H. Lestiana dan A. Mulyono. 2012. Upaya Konservasi Tanah dan Air dengan Agroforestry di Subang Selatan. Prosiding pemaparan hasil penelitian pusat penelitian geoteknologi LIPI-2012.

Naharuddin, N. 2018. Sistem Pertanian Konservasi Pola Agroforestry dan Hubungannya dengan Tingkat Erosi di Wilayah Sub-DASWuno, Das Palu, Sulawesi Tengah. Jurnal Wilayah dan Lingkungan. Vol. 6 No. 3 ; 183-192.

Rianse U. 2010. Agroforestry Solusi dan Ekonomi Pengelolaan Sumberdaya Hutan. Bandung : Alfabeta.

Sardjono, M.A., T. Djogo, H.S. Arifin dan N. Wijayanto. 2003. Klasifikasi dan pola kombinasi komponen agroforestry. Bogor : World Agroforestry Centre (ICRAF).

Senoadji, G. 2012. Pengelolaan lahan dengan system agroforestry oleh masyarakat Baduy di Banten Selatan. Jurnal Bumu Lestari, vol 12 No.2 ; 283-293.

Silaya, T.M., Tjoa, M. 2013. Kajian Aspek Sosial Pola Agroforestry Tradisional (Dusung) di Pulau Ambon. Prosiding Seminar Nasional Agroforestry 2013.

Widianto, N. Wijayanto dan D. Suprayogo. 2003. Pengelolaan dan pengembangan agroforestry. Bogor : World Agroforestry Centre (ICRAF).

Yunasfi. 2007. Penerapan Sistem Agroforestry Pada Program Penghijauan dan Konservasi Tanah (Kegiatan Agroforestry Di luar Kawasan Hutan Skripsi. Fakultas Pertanian Universitas Sumatera Utara. 